\title{
The impact of high-flow nasal cannula oxygen therapy on exercise capacity in fibrotic interstitial lung disease: a proof-of- concept randomized controlled crossover trial
}

Atsushi Suzuki ${ }^{1,2^{*}}$, Masahiko Ando ${ }^{3}$, Tomoki Kimura', Kensuke Kataoka', Toshiki Yokoyama', Eiichi Shiroshita ${ }^{4}$ and Yasuhiro Kondoh ${ }^{1}$

\begin{abstract}
Background: Patients with fibrotic interstitial lung disease (FILD) often experience gas exchange abnormalities and ventilatory limitations, resulting in reduced exercise capacity. High-flow nasal cannula (HFNC) oxygen therapy is a novel treatment, whose physiological beneficial effects have been demonstrated in various clinical settings. We hypothesized that HFNC oxygen therapy might be superior to conventional oxygen therapy for improving exercise capacity in FILD patients.

Methods: We performed a prospective randomized controlled crossover trial with a high-intensity constant work-rate endurance test (CWRET) using HFNC ( $\left.50 \mathrm{~L} / \mathrm{min} \mathrm{FiO}_{2} 0.5\right)$ and a venturi mask $(\mathrm{VM})\left(15 \mathrm{~L} / \mathrm{min}, \mathrm{FiO}_{2}\right.$ 0.5) for oxygen delivery in FILD patients. The primary outcome variable was endurance time. The secondary outcome variables were $\mathrm{SpO}_{2}$, heart rate, Borg scale (dyspnea and leg fatigue), and patient's comfort.
\end{abstract}

Results: Seven hundred and eleven patients were screened and 20 eligible patients were randomized. All patients completed the trial. The majority of patients were good responders to VM and HFNC compared with the baseline test VM 75\%; HFNC 65\%). There was no significant difference in endurance time between HFNC and VM (HFNC 6.8 [95\% Cl 4.3-9.3] min vs VM 7.6 [95\% Cl 5.0-10.1] min, $p=0.669)$. No significant differences were found in other secondary endpoints. Subgroup analysis with HFNC good responders revealed that HFNC significantly extended the endurance time compared with VM NM 6.4 [95\%Cl 4.58.3] min vs HFNC 7.8 [95\%Cl 5.8-9.7] min, $p=0.046$ ), while no similar effect was observed in the VM good responders.

Conclusions: HFNC did not exceed the efficacy of VM on exercise capacity in FILD, but it may be beneficial if the settings match. Further large studies are needed to confirm these findings.

Trial registration: UMIN-CTR: UMIN000021901.

Keywords: Fibrotic interstitial lung disease, High-flow nasal cannula, Oxygen therapy, Exercise capacity, Pulmonary rehabilitation, Health status

\footnotetext{
*Correspondence: suzukia@med.nagoya-u.ac.jp

'Department of Respiratory Medicine and Allergy, Tosei General Hospital, 160 Nishioiwake-cho, Seto, Aichi 489-8642, Japan

2Department of Respiratory Medicine, Nagoya University Graduate School of Medicine, Nagoya, Aichi, Japan

Full list of author information is available at the end of the article
}

(c) The Author(s). 2020 Open Access This article is licensed under a Creative Commons Attribution 4.0 International License, which permits use, sharing, adaptation, distribution and reproduction in any medium or format, as long as you give appropriate credit to the original author(s) and the source, provide a link to the Creative Commons licence, and indicate if changes were made. The images or other third party material in this article are included in the article's Creative Commons licence, unless indicated otherwise in a credit line to the material. If material is not included in the article's Creative Commons licence and your intended use is not permitted by statutory regulation or exceeds the permitted use, you will need to obtain permission directly from the copyright holder. To view a copy of this licence, visit http://creativecommons.org/licenses/by/4.0/ The Creative Commons Public Domain Dedication waiver (http://creativecommons.org/publicdomain/zero/1.0/) applies to the data made available in this article, unless otherwise stated in a credit line to the data. 


\section{Background}

Fibrotic interstitial lung diseases (FILD) are progressive chronic lung diseases, including idiopathic pulmonary fibrosis (IPF) and other forms of ILD [1, 2]. Patients with FILD often experience exertion dyspnea and reduced exercise capacity, which leads to impairment of health status and poor prognosis [ 3-5]. Interventions to enhance exercise capacity and physical activity have an important role for the management of FILD patients.

Recently, there is a growing body of evidence that supplemental oxygen is effective in improving the exercise capacity of FILD patients. A previous doubleblind, placebo-controlled, randomized crossover trial demonstrated that ambulatory oxygen did not improve exercise capacity and exertion dyspnea compared with placebo-air [6]. On the other hand, a recent prospective, open-label, crossover randomized controlled trial $(\mathrm{AmbOx})$ showed that supplemental oxygen improves exercise capacity and exertional dyspnea compared with placebo-air in FILD patients [7]. Another randomized crossover trial also showed that supplemental oxygen provided through an oxygen conserving device improved endurance time and desaturation in FILD patients [8]. Based on these findings, short-burst supplemental oxygen during exercise is becoming common practice for FILD patients [9].

The high-flow nasal cannula (HFNC) is a novel device delivering heated and humidified oxygen via a nasal cannula at a maximum flow of $60 \mathrm{l} / \mathrm{min}$.

This generates low levels of positive pressure in the upper airways and decreases physiological dead space by flushing out expired carbon dioxide.

Its beneficial effects and utility have been widely demonstrated in various clinical settings [10-13]. However, few studies have assessed the efficacy of HFNC on exercise capacity in patients with FILD.

We hypothesized that HFNC oxygen therapy might be superior to conventional oxygen therapy for improving exercise capacity in FILD patients. To assess this hypothesis, we performed a proof-of-concept prospective randomized controlled crossover trial with a highintensity constant work-rate endurance test (CWRET) using HFNC and a venturi mask (VM) for oxygen delivery in patients with FILD.

\section{Methods}

\section{Study population}

This prospective randomized controlled crossover trial was performed at Tosei General Hospital in Japan from April 2016. This study was carried out in accord with the principles of the Declaration of Helsinki and approved by the Tosei General Hospital Institutional Review Board (IRB No. 554). The trial was registered in the university hospital medical information network Clinical Trial Registry (UMIN-CTR) (UMIN000021901). All participants provided written informed consent before participation.

Eligible patients were aged $\geq 18$ years who had been diagnosed with FILD in accordance with the previously established criteria [1, 2]. Exclusion criteria were $\mathrm{SpO}_{2}>$ $88 \%$ during the baseline CWRET, need for high concentration oxygen at rest $\left(\mathrm{FiO}_{2}>50 \%\right)$, coexistence of chronic obstructive pulmonary disease (COPD) (forced expiratory volume in $1 \mathrm{sec}$ [FEV1] / forced vital capacity $[\mathrm{FVC}]<0.70$ ), pneumothorax, pneumomediastinum, an unstable disease, and a history of acute exacerbation within the last 1 month.

\section{Study design}

The high-intensity CWRET is considerably more responsive than incremental exercise tests or the 6-min walking test to assess the effects of interventions [14, 15]. According to these studies, we selected the highintensity CWRET to assess the efficacy of HFNC on exercise capacity.

Based on previous studies, a sample size of 16 patients with randomization was required to detect a mean difference in the endurance time of $2 \mathrm{~min}$ between $\mathrm{VM}$ and HFNC (8 patients in each group), with a power of $80 \%$ at a two-sided alpha level of $0.05[16,17]$. Considering an expected dropout rate of $10 \%$ in a previous exercise training study of FILD patients, a total of 20 patients were recruited [16].

\section{Randomization and interventions}

Eligible patients first performed a symptom limited incremental exercise test to evaluate the patient's maximal exercise capacity, using electrically braked cycloergometer (AEROBIKE 800 / AEROBIKE 75XL III; Combi corporation, Tokyo, Japan). The incremental test was performed on room air or in each oxygen flow at rest according to the American Thoracic Society (ATS) /American College of Chest Physicians (ACCP) statement [18]. On another day, patients performed a highintensity CWRET with $80 \%$ of the maximum work-load determined by symptom limited incremental exercise test. Subjects continued at a pedaling rate of 60 cycles/ min until they could no longer continue. Patients with $\mathrm{SpO}_{2}>88 \%$ during the CWRET were excluded before randomization (Fig. 1).

After screening, we finally recruited a total of 20 patients. All patients were randomly allocated into two groups using the block randomization technique (blocks of four patients) in a 1:1 ratio. In group $\mathrm{A}$, a high-intensity CWRET using VM was performed on the first day, and a test using HFNC was performed on the following day. In group $\mathrm{B}$, a high-intensity 


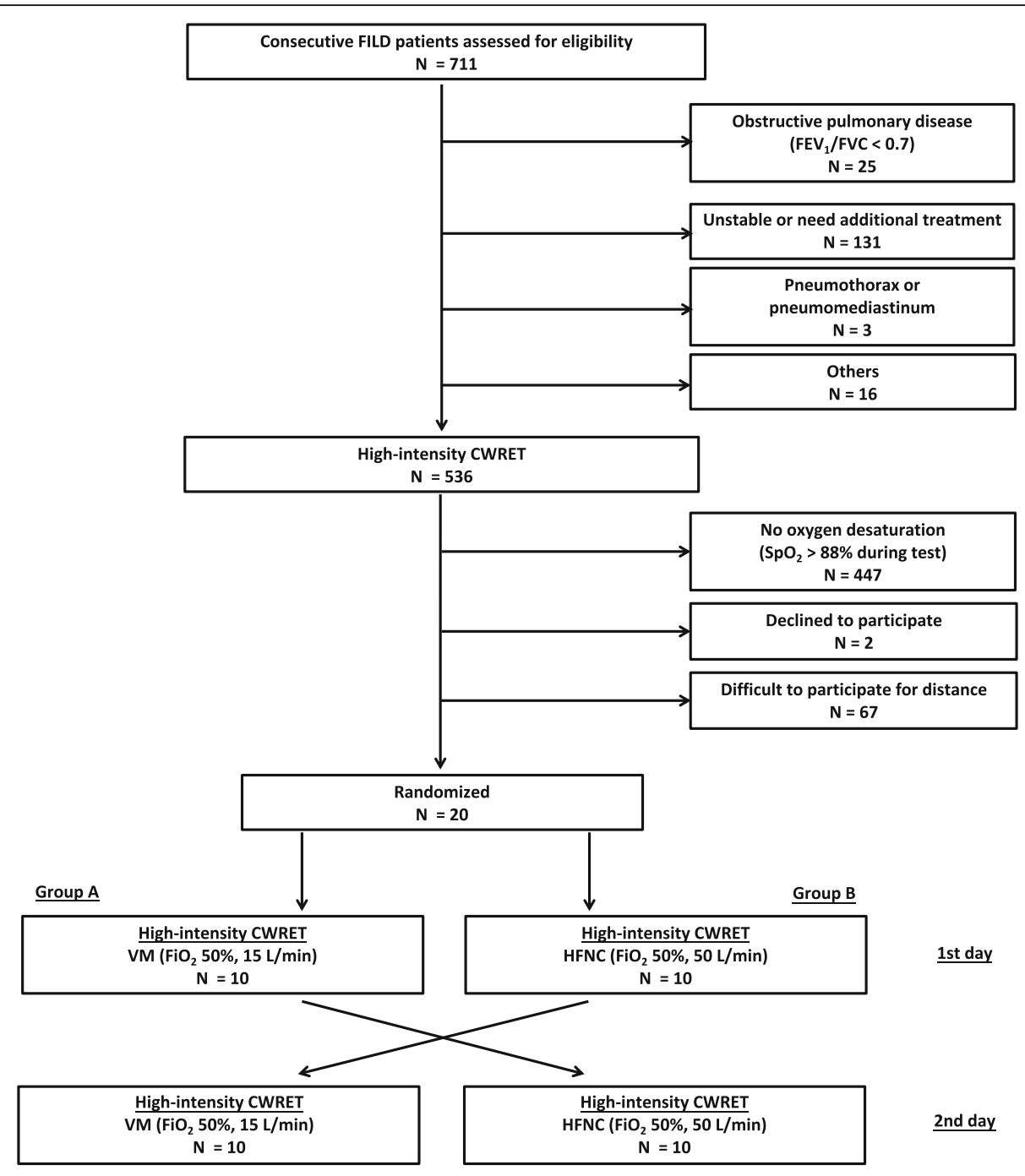

Fig. 1 Patient flow chart

CWRET using HFNC was performed on the first day, and a test using VM was performed on the following day. The setting for VM (Silente $\mathrm{O}_{2}$ Venturi, Intersurgical Ltd., Berkshire, UK) was a $\mathrm{FiO}_{2}$ of $50 \%$, with an oxygen flow of $15 \mathrm{~L} / \mathrm{min}$. The setting for HFNC (PMB-5000 and PMH 7000 PLUS, Pacific Medico Co., Ltd., Tokyo, Japan) was a $\mathrm{FiO}_{2}$ of $50 \%$, with a humidified oxygen flow of $50 \mathrm{l} / \mathrm{min}$. Endurance time was measured on each test. $\mathrm{SpO}_{2}$ and heart rate (HR) were monitored throughout the test by pulse oximetry (PULSOX-3, Konica Minolta Japan, Inc., Tokyo, Japan). Subjects were asked to rate their dyspnea and leg fatigue every minute during the test using the modified Borg scale. Isotime values for dyspnea and leg fatigue were defined at the point of termination of the shorter CWRET [15]. Patient's comfort with each device was assessed at the end of each trial, using a 0 to 10 numerical rating scale $(10=$ no discomfort $)$.

\section{Study outcomes}

The primary outcome variable was endurance time. The secondary outcome variables were $\mathrm{SpO}_{2}, \mathrm{HR}$, modified Borg scale, patient's comfort with each device, and adverse events during endurance exercise test.

\section{Statistical analysis}

Categorical variables were summarized by frequency. Continuous variables were expressed as mean \pm standard deviation (SD) or mean (95\% confidence interval [CI]). For comparisons with the data for categorical variables or continuous variables between groups, a chi-squared test or Student's t-test were used. A generalized linear 
mixed-effects model was applied for both primary and secondary endpoints; the model included device, sequence, and period as fixed effects, and subject within sequence as a random effect. The Bonferroni post-hoc test was performed for multiple comparisons of groups. As a sub-analysis, we compared VM and HFNC data with baseline CWRET. A CWRET good responder was defined as a patient with $>100 \mathrm{~s}$ or $33 \%$ improvement of endurance time from baseline CWRET [14]. Subgroup analyses of endpoints in VM/HFNC good responders were conducted. We also investigated the relationship between VM/HFNC non-responders and pulmonary hypertension $(\mathrm{PH})$ assessed by either echocardiography (right ventricular systolic pressure $>35 \mathrm{mmHg}$ ) or right heart catheterization (mean pulmonary artery pressure $\geq$ $25 \mathrm{mmHg})[19,20]$. All tests were performed at a

Table 1 Patient characteristics

\begin{tabular}{|c|c|c|c|c|}
\hline & All & Group A & Group B & $P$ value \\
\hline Number & 20 & 10 & 10 & \\
\hline Age, years & $70.7 \pm 7.6$ & $73.0 \pm 7.6$ & $68.5 \pm 7.2$ & 0.192 \\
\hline Sex, M/F & $19 / 1$ & $10 / 0$ & $9 / 1$ & 0.305 \\
\hline $\mathrm{BMl}, \mathrm{Kg} / \mathrm{m}^{2}$ & $22.3 \pm 5.1$ & $20.7 \pm 2.7$ & $24.0 \pm 6.4$ & 0.149 \\
\hline \multicolumn{5}{|l|}{ Smoking status } \\
\hline Ever/Never & $19 / 1$ & $9 / 1$ & $10 / 0$ & 0.305 \\
\hline Pack-years & $53.7 \pm 40.4$ & $41.8 \pm 30.7$ & $65.6 \pm 46.8$ & 0.196 \\
\hline $\mathrm{mMRC}$ & $2.7 \pm 1.0$ & $2.8 \pm 0.9$ & $2.6 \pm 1.2$ & 0.676 \\
\hline FVC, \%pred. & $60.0 \pm 14.7$ & $62.9 \pm 19.2$ & $57.0 \pm 8.4$ & 0.386 \\
\hline $\mathrm{FEV}_{1} / \mathrm{FVC}_{1} \%$ & $88.0 \pm 8.6$ & $88.5 \pm 7.7$ & $87.6 \pm 9.8$ & 0.821 \\
\hline DLco, \%pred.* & $32.5 \pm 15.2$ & $32.3 \pm 15.0$ & $32.8 \pm 16.4$ & 0.953 \\
\hline RV, \%pred.** & $59.7 \pm 23.9$ & $66.8 \pm 27.2$ & $52.8 \pm 19.4$ & 0.258 \\
\hline Oxygen therapy, Yes & $8(40 \%)$ & $3(30 \%)$ & $5(50 \%)$ & 0.361 \\
\hline Flow at rest, L/min & $2.2 \pm 1.5$ & $2.5 \pm 2.3$ & $2.0 \pm 1.0$ & \\
\hline $\mathrm{PaCO}_{2}$, torr & $43.2 \pm 5.4$ & $44.2 \pm 5.6$ & $42.3 \pm 5.2$ & 0.433 \\
\hline \multicolumn{5}{|l|}{ FILD classification, n } \\
\hline IPF & 12 & 5 & 7 & \\
\hline NSIP & 1 & 1 & 0 & \\
\hline CTD-ILD & 2 & 1 & 1 & \\
\hline Unclassifiable IIP & 5 & 3 & 2 & \\
\hline Pulmonary hypertension*** & $12(60 \%)$ & $6(60 \%)$ & $6(60 \%)$ & 1.000 \\
\hline RVSP $\geq 35 \mathrm{mmHg}$ & $10 / 15$ & $5 / 6$ & $5 / 9$ & \\
\hline MPAP $\geq 25 \mathrm{mmHg}$ & $6 / 18$ & $4 / 9$ & $2 / 9$ & \\
\hline \multicolumn{5}{|l|}{ Baseline CWRET } \\
\hline Endurance time, min & $3.9 \pm 3.3$ & $3.5 \pm 1.1$ & $4.4 \pm 4.6$ & 0.518 \\
\hline Min $\mathrm{SpO}_{2}, \%$ & $77.7 \pm 6.6$ & $76.9 \pm 7.4$ & $78.5 \pm 5.9$ & 0.601 \\
\hline Max HR, bpm & $121.2 \pm 17.9$ & $128.0 \pm 11.4$ & $114.3 \pm 21.0$ & 0.086 \\
\hline \multicolumn{5}{|l|}{ Final Borg scale } \\
\hline Dyspnea & $6.9 \pm 2.1$ & $7.2 \pm 1.9$ & $6.5 \pm 2.3$ & 0.468 \\
\hline Leg fatigue & $6.2 \pm 2.8$ & $7.0 \pm 1.9$ & $5.4 \pm 3.3$ & 0.188 \\
\hline
\end{tabular}

Group A: venturi mask (VM) $\rightarrow$ high-flow nasal cannula (HFNC)

Group B: HFNC $\rightarrow$ VM

Data are presented as number (\%) or mean \pm standard deviation (SD)

$P$-value from chi-squared test or Student's t-test

${ }^{*} n=17$ (A: $n=9$, B: $\left.n=8\right),{ }^{*} n=16($ A: $n=8$, B: $n=8)$, ${ }^{* * *}$ Pulmonary hypertension was assessed by echocardiography (right ventricular systolic pressure $>35$ $\mathrm{mmHg}$ ) or right heart catheterization (mean pulmonary artery pressure $\geq 25 \mathrm{mmHg}$ )

$B M I$ body mass index, CTD connective tissue disease, CWRET constant work-rate endurance test, DLco diffusion capacity for carbon monoxide, FEV ${ }_{1}$ forced expiratory volume in $1 \mathrm{~s}$, FVC forced vital capacity, IIP idiopathic interstitial pneumonia, FILD fibrotic interstitial lung disease, HR heart rate, IPF idiopathic pulmonary fibrosis, $m M R C$ the modified Medical Research Council dyspnea scale, MPAP mean pulmonary artery pressure, NSIP non-specific interstitial pneumonia, $\mathrm{PaO}_{2}$ partial pressure of oxygen, $\mathrm{PaCO}_{2}$ partial pressure of carbon dioxide, $R \mathrm{~V}$ residual volume, RVSP right ventricular systolic pressure 
significance level of $p<0.05$. Analysis was completed using IBM SPSS statistics ver. 21 (IBM Corp. Armonk, NY, USA).

\section{Results}

\section{Baseline characteristics}

Between April 2016 and June 2017, 711 patients with FILD were screened for eligibility. After screening, 20 patients were enrolled and randomized for the prospective crossover trial as planned (Fig. 1). The characteristics of the 20 patients are summarized in Table 1. There were no significant differences in any of the data between group A and group B. There were also no significant differences in any of the data between IPF and non-IPF-FILD cases (Supplementary Table S1). All patients completed the trial.

\section{Primary and secondary outcomes}

The median duration between the baseline CWRET and randomization was 2 days (interquartile range 2-7 days). Table 2 shows the comparison of primary and secondary endpoints between VM and HFNC. Compared with the baseline CWRET, the majority of patients were good responders to VM and HFNC (VM $n=15,75 \%$; HFNC $n=13,65 \%$ ) (Table 2). HFNC did not exceed the efficacy of VM in endurance time (HFNC 6.8 [95\% confidence interval (CI) 4.3-9.3] min vs VM 7.6 [95\% CI 5.010.1] $\min , p=0.669)$. There were no significant differences in other secondary endpoints. Trend graph of each variable during endurance exercise tolerance test are shown in Fig. 2 (the data of each subject are shown in supplementary Figure S1, S2, S3 and S4). Two patients complained about nasal pain from HFNC, but it improved immediately. No other adverse events were observed.

\section{Sub-analysis compared with the baseline CWRET}

As a sub-analysis, we compared VM and HFNC data with baseline CWRET (Table 3). Compared with the baseline test, both VM and HFNC significantly improved min $\mathrm{SpO}_{2}$ (baseline 77.7\%; VM 89.4\%; HFNC 89.7\%) and isotime Borg dyspnea scale (baseline 6.6; VM 4.5; HFNC 3.9). HFNC also improved isotime Borg leg fatigue scale (baseline 6.0, HFNC 3.7).

\section{Subgroup analysis in HFNC good responders}

Among HFNC good responders $(n=13)$, the majority were also VM good responders $(n=11,85 \%)$. In this subgroup, HFNC was superior in 6 patients, VM was superior in 1 patient, and the two were equivalent in 6 patients (superior: $>100 \mathrm{~s}$ or $33 \%$ improvement in endurance time). HFNC clearly reduced exertional dyspnea compared to VM in some patients (Case 1, 11, 12, 16, 19) (Supplementary Figure S3). Subgroup analysis of HFNC responders revealed that HFNC significantly extended the endurance time compared with VM (VM 6.4 [95\%CI 4.5-8.3] min vs HFNC 7.8 [95\%CI 5.8-9.7] min, $p=0.046)$, while no similar effect was observed in the analysis of VM responders (Table 4, Supplementary Table S2). No significant differences were found in baseline characteristics between HFNC good responders and non-responders (Supplementary Table S3).

\section{Relationship between VM/HFNC responders and PH}

Echocardiography or right heart catheterization was performed in all patients, and 12 patients were diagnosed with PH (Table 1). There was no significant difference in the proportion of HFNC non-responders between patients with and without $\mathrm{PH}(\mathrm{PH} 33 \%$ vs non- $\mathrm{PH} 38 \%$; chi-squared test, $p$-value 0.848$)$. Additionally, there was no significant difference in the proportion of VM non-

Table 2 Primary and secondary endpoints (VM vs HFNC)

\begin{tabular}{|c|c|c|c|c|}
\hline & VM & HFNC & Difference $(95 \% \mathrm{Cl})$ & $P$-value \\
\hline Good responder $^{*}$ & $15(75 \%)$ & $13(65 \%)$ & & \\
\hline \multicolumn{5}{|l|}{ Primary endpoint } \\
\hline Endurance time, min & $7.6(5.0-10.1)$ & $6.8(4.3-9.3)$ & $-0.8(-4.4-2.8)$ & 0.669 \\
\hline \multicolumn{5}{|l|}{ Secondary endpoint } \\
\hline $\operatorname{Min} \mathrm{SpO}_{2}, \%$ & $89.4(85.1-93.7)$ & $89.7(85.3-94.0)$ & $0.3(-5.8-6.3)$ & 0.934 \\
\hline Max HR, bpm & $124.2(115.9-132.4)$ & $120.8(112.5-129.1)$ & $-3.8(-11.7-4.2)$ & 0.345 \\
\hline Isotime Borg scale (dyspnea) & $5.9(4.6-7.1)$ & $5.9(4.7-7.1)$ & $0.1(-1.7-1.8)$ & 0.955 \\
\hline Isotime Borg scale (leg fatigue) & $5.7(4.2-7.2)$ & $5.4(3.9-6.8)$ & $-0.3(-2.4-1.8)$ & 0.757 \\
\hline Final Borg scale (dyspnea) & $7.0(5.8-8.1)$ & $6.6(5.4-7.8)$ & $-0.4(-2.0-1.3)$ & 0.672 \\
\hline Final Borg scale (leg fatigue) & $6.4(4.9-7.9)$ & $6.3(4.8-7.8)$ & $-0.1(-2.3-2.1)$ & 0.926 \\
\hline Patient comfort of device & $7.8(6.7-8.9)$ & $6.3(5.2-7.4)$ & $-1.5(-3.1-0.1)$ & 0.067 \\
\hline
\end{tabular}

Data are presented as number (\%) or mean $(95 \% \mathrm{Cl})$

HFNC high-flow nasal cannula, $\mathrm{HR}$ heart rate, $\mathrm{SpO}_{2}$ saturation of peripheral oxygen, VM venturi mask

*Good responder was defined as a patient with $>100 \mathrm{~s}$ or $33 \%$ improvement of endurance time from baseline CWRET,

${ }^{* *}$ Calculated by generalized linear mixed-effects model with fixed factors for each device, sequence, and period, and a random factor for subject within sequence 


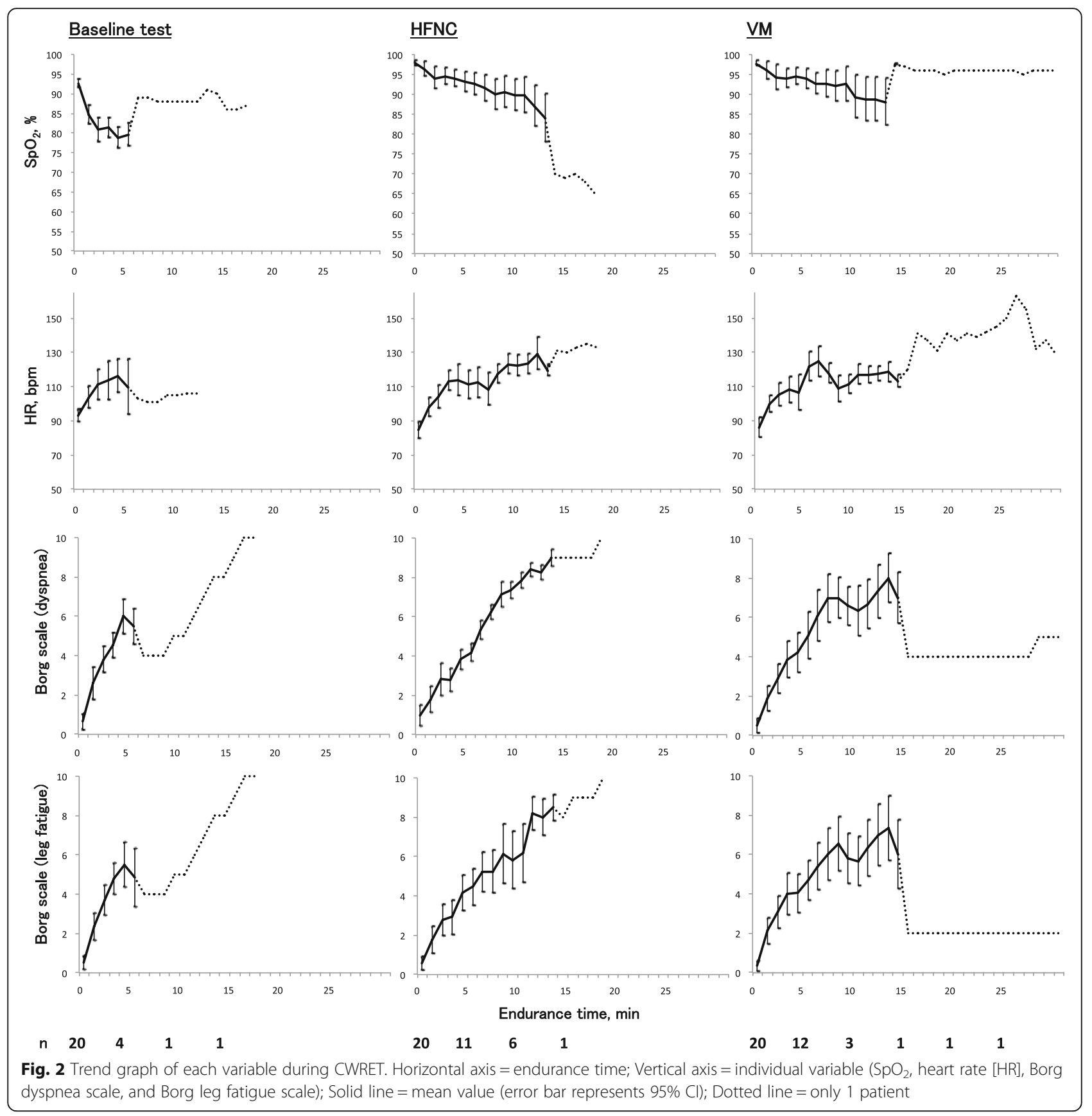

responders between patients with and without $\mathrm{PH}(\mathrm{PH}$ $33 \%$ vs non-PH $12 \%$; chi-squared test, $p$-value 0.292 ).

\section{Discussion}

To the best of our knowledge, this is the first randomized crossover trial of an exercise test using HFNC in FILD patients. Contrary to our expectations, this study did not meet the prespecified endpoints. However, the majority of patients responded well to HFNC, and the effect was superior to VM in some patients. Moreover, HFNC significantly extended the endurance time compared with VM in the subgroup analysis. Although we could not prove its efficacy due to the small sample size and unchanged settings, HFNC oxygen therapy may improve exercise capacity in FILD patients.

HFNC clearly improved endurance time and exertional dyspnea in a limited number of patients (Case $1,11,12,16,19)$. We may conjecture several potential mechanisms for these beneficial effects. First, washout of the physiological dead space may have improved patients' work of breathing. Bräunlich et al. 
Table 3 Sub-analysis compared with the baseline CWRET

\begin{tabular}{|c|c|c|c|}
\hline & Mean & $95 \% \mathrm{Cl}$ & $P$-value ${ }^{*}$ \\
\hline \multicolumn{4}{|c|}{ Endurance time, $\min$} \\
\hline Baseline test & 3.9 & $1.7-6.2$ & Ref. \\
\hline VM & 7.6 & $5.3-9.8$ & 0.076 \\
\hline HFNC & 6.8 & $4.6-9.0$ & 0.226 \\
\hline \multicolumn{4}{|l|}{$\operatorname{Min} \mathrm{SpO}_{2}, \%$} \\
\hline Baseline test & 77.7 & $73.8-81.6$ & Ref. \\
\hline VM & 89.4 & $85.5-93.3$ & $<0.001$ \\
\hline HFNC & 89.7 & $85.8-93.5$ & $<0.001$ \\
\hline \multicolumn{4}{|l|}{ Max HR, bpm } \\
\hline Baseline test & 121.2 & $113.2-129.1$ & Ref. \\
\hline VM & 124.2 & $116.2-132.1$ & 1.000 \\
\hline HFNC & 120.8 & $112.8-128.8$ & 1.000 \\
\hline \multicolumn{4}{|c|}{ Isotime Borg scale (dyspnea) } \\
\hline Baseline test & 6.6 & $5.4-7.7$ & Ref. \\
\hline VM & 4.5 & $3.4-5.6$ & 0.040 \\
\hline HFNC & 3.9 & $2.8-5.1$ & 0.006 \\
\hline \multicolumn{4}{|c|}{ Isotime Borg scale (leg fatigue) } \\
\hline Baseline test & 6.0 & $4.7-7.3$ & Ref. \\
\hline VM & 4.3 & $3.0-5.6$ & 0.188 \\
\hline HFNC & 3.7 & $2.4-4.9$ & 0.035 \\
\hline \multicolumn{4}{|c|}{ Final Borg scale (dyspnea) } \\
\hline Baseline test & 6.9 & $5.8-7.9$ & Ref. \\
\hline VM & 7.0 & $5.9-8.0$ & 1.000 \\
\hline HFNC & 6.6 & $5.5-7.7$ & 1.000 \\
\hline \multicolumn{4}{|c|}{ Final Borg scale (leg fatigue) } \\
\hline Baseline test & 6.2 & $4.7-7.6$ & Ref. \\
\hline VM & 6.4 & $5.0-7.8$ & 1.000 \\
\hline HFNC & 6.3 & $4.9-7.7$ & 1.000 \\
\hline
\end{tabular}

"Calculated by generalized linear mixed-effects model with fixed factors for each device, sequence, and period, and a random factor for subject within sequence. The Bonferroni post-hoc test was performed for multiple comparisons of groups

[21] reported that HFNC decreases respiratory rate and carbon dioxide $\left(\mathrm{CO}_{2}\right)$ levels in patients with IPF and COPD. A recent randomized controlled crossover trial also showed that HFNC decreases respiratory rate and $\mathrm{CO}_{2}$ levels in stable COPD patients [22]. These beneficial effects may have contributed to improving exercise capacity and exertional dyspnea. Second, improvement in mucosal dryness with heated and humidified oxygen may have improved patient comfort during exercise. Chanques et al. [23] reported that under-humidified high-flow oxygen therapy was associated with patients' discomfort and mouth-throat dryness. HFNC can deliver heated and humidified oxygen, which may have led to greater comfort during exercise. Finally, positive airway pressure may have improved dynamic hyperinflation and alveolar collapse. A previous report showed that HFNC increases airway pressure as flow increases [24]. In a recent clinical study, HFNC improved the tidal volume and end-expiratory lung volume compared with conventional oxygen therapy in COPD patients [13]. Even though we excluded patients with concurrent airflow limitations (FEV1/FVC $<0.7)$, these effects might be associated with the improvement of oxygenation and exercise capacity. Unfortunately, we could not assess physiological variables including end-expiratory pressure and end tidal $\mathrm{CO}_{2}$. Future researches may reveal the exact mechanisms.

Conversely, we found that HFNC was inferior to VM in a few patients (Case 6, 7, 9). A recent experimental study using an airway model made with a 3D printer demonstrated that increasing the flow rate of HFNC generates higher positive end-expiratory pressure (PEEP) but does not necessarily increase the washout effects [25]. In our study, two patients complained about nasal pain, although it improved immediately. We suppose that the flow rate of $50 \mathrm{~L} / \mathrm{min}$ might have been too strong for them. Although the flow rate was determined with reference to previous studies, further validation studies will be required [10-12].

Differences in pathophysiology between FILD and COPD should be considered. Although the pathophysiology of both diseases is complex, FILD is mainly affected by restrictive impairment, while COPD is mainly affected by airflow limitation. Previous studies have demonstrated that non-invasive ventilatory support by continuous positive airway pressure (CPAP) and pressure support ventilation (PSV) improves exercise performance and exertional dyspnea in COPD patients [26, 27]. On the other hand, Moderno et al. [28] showed that CPAP did not improve exercise performance compared with proportional assist ventilation (PAV) in IPF patients. Considering these findings, a decrease in the work of breathing may be more important than an increase in PEEP in improving the exercise capacity in FILD patients. The most appropriate individual settings to decrease the work of breathing may improve the exercise performance of HFNC non-responders.

In the present study, both VM and HFNC significantly improved oxygenation and exertion dyspnea compared with the baseline test. There was no significant difference in the proportion of responders between patients with and without $\mathrm{PH}$. Our findings emphasize the importance of supplemental oxygen for improving exercise capacity in FILD patients. Furthermore, HFNC has been reported to improve health status and exercise capacity in COPD patients within a mid-long-term [29, 30]. An exercise training significantly improved exercise capacity and health status in patients with FILD [31-33]. 
Table 4 Subgroup analysis of endpoints in HFNC good responders

\begin{tabular}{|c|c|c|c|c|}
\hline$N=13$ & VM & HFNC & Difference $(95 \% \mathrm{Cl})$ & $P$-value ${ }^{* *}$ \\
\hline \multicolumn{5}{|l|}{ Primary endpoint } \\
\hline Endurance time, min & $6.4(4.5-8.3)$ & $7.8(5.8-9.7)$ & $1.4(0.0-2.7)$ & 0.046 \\
\hline \multicolumn{5}{|l|}{ Secondary endpoint } \\
\hline $\operatorname{Min~} \mathrm{SpO}_{2}, \%$ & $89.7(84.3-95.0)$ & $88.6(83.2-93.9)$ & $-1.1(-3.4-1.2)$ & 0.319 \\
\hline Max HR, bpm & $124.2(112.4-136.1)$ & $120.5(108.6-132.4)$ & $-3.7(-14.8-7.4)$ & 0.478 \\
\hline Isotime Borg scale (dyspnea) & $6.7(5.3-8.1)$ & $6.4(5.0-7.8)$ & $-0.3(-1.6-1.0)$ & 0.632 \\
\hline Isotime Borg scale (leg fatigue) & $6.3(4.5-8.1)$ & $6.0(4.2-7.7)$ & $-0.4(-1.8-1.1)$ & 0.583 \\
\hline Final Borg scale (dyspnea) & $7.3(5.8-8.8)$ & $7.2(5.7-8.6)$ & $-0.2(-0.5-0.2)$ & 0.153 \\
\hline Final Borg scale (leg fatigue) & $6.6(4.7-8.6)$ & $6.9(4.9-8.8)$ & $0.3(-0.8-1.4)$ & 0.614 \\
\hline Patient comfort of device & $8.4(7.2-9.6)$ & $7.3(6.1-8.5)$ & $-1.0(-2.7-0.7)$ & 0.220 \\
\hline
\end{tabular}

Data are presented as number $(\%)$ or mean $(95 \% \mathrm{Cl})$

HFNC high-flow nasal cannula, $\mathrm{HR}$ heart rate, $\mathrm{SpO}_{2}$ saturation of peripheral oxygen, VM venturi mask

"Good responder was defined as a patient with $>100 \mathrm{~s}$ or $33 \%$ improvement in endurance time from baseline CWRET,

${ }^{* *}$ Calculated by generalized linear mixed-effects model with fixed factors for each device, sequence, and period, and a random factor for subject within sequence

Combining appropriate oxygen therapy with exercise training may enhance its effectiveness in FILD patients.

Our study has some limitations. First, this is a small single-center study. Second, the heterogeneity of FILD needs to be considered. Recent clinical studies have demonstrated the similarities in genetics, pathophysiology, and clinical course between IPF and non-IPFFILD [34-36]. Additionally, previous reports showed a reduced exercise capacity in patients with non-IPF-FILD, similar to that in patients with IPF $[37,38]$. Considering these findings, we recruited patients with all forms of FILD. Third, the carryover effects may need to be considered. To minimize the potential bias and carryover effects, we used a generalized linear mixed-effects model adjusted for device, sequence, and period as fixed effects, and subject within sequence as a random effect. Finally, gender split and racial differences may need to be considered since most patients were male and all were Japanese.

\section{Conclusions}

We first examined the efficacy of HFNC oxygen therapy on exercise capacity in FILD patients. In this study, HFNC did not exceed the efficacy of VM, however, it may be beneficial if the settings match. Predetermining comfortable settings for each patient may increase the effectiveness of HFNC. Further studies will be required to confirm the potential benefits of HFNC for improving exercise capacity in FILD patients.

\section{Supplementary information}

Supplementary information accompanies this paper at https://doi.org/10. 1186/s12890-020-1093-2.

Additional file 1: Table S1. Comparison of baseline characteristic between IPF and non-IPF. Table S2. Subgroup analysis of endpoints in
VM good responders. Table S3. Comparison of baseline characteristics between HFNC good responders and non-responders. Figure S1. Trend graph of $\mathrm{SpO}_{2}$ during endurance exercise tolerance test in each subject. Figure S2. Trend graph of heart rate (HR) during endurance exercise tolerance test in each subject. Figure S3. Trend graph of Borg scale (dyspnea) during endurance exercise tolerance test in each subject. Figure S4. Trend graph of Borg scale (leg fatigue) during endurance exercise tolerance test in each subject.

\section{Abbreviations}

COPD: Chronic obstructive pulmonary disease; CPAP: Continuous positive airway pressure; CWRET: Constant work-rate endurance test; FEV $\mathrm{F}_{1}$ : Forced expiratory volume in one second; FILD: Fibrotic interstitial lung disease; FVC: Forced vital capacity; HFNC: High-flow nasal cannula; IIP: Idiopathic interstitial pneumonia; IPF: Idiopathic pulmonary fibrosis; NSIP: Non-specific interstitial pneumonia; PEEP: Positive end-expiratory pressure; $\mathrm{PH}$ : Pulmonary hypertension; VM: Venturi mask

\section{Acknowledgements}

The authors thank the following people for their support of study: Tomoya Ogawa, Fumiko Watanabe, Jun Hirasawa, Takuya Mishima, Takuro Furukawa, Yusuke Nagae, Kazuya Shingai, and Yuko Kokubo, Department of Rehabilitation, Tosei General Hospital; Sayaka Tsukada, Department of Medical Engineering, Tosei General Hospital.

\section{Authors' contributions}

AS had full access to the data and takes responsibility for the integrity of the data and accuracy of the analysis. Study concept and design: AS, MA, TK, KK, TY, ES, YK. Acquisition of data: AS, TK, KK, TY. Statistical analysis: AS, MA. Interpretation of data: AS, MA, YK. Drafting of the initial manuscript: AS, MA, YK. Critical revision of final manuscript: AS, MA, TK, KK, TY, ES, YK. Approve the final version of the manuscript: AS, MA, TK, KK, TY, ES, YK.

\section{Funding}

This research was funded by Pacific Medico Co.,Ltd. The sponsor was involved in designing the study, but not involved in the collection, analysis, interpretation of data, or writing the manuscript.

Availability of data and materials

All data generated or analyzed during this study are included in this published article and its supplementary information files.

\section{Ethics approval and consent to participate}

This study was carried out in accord with the principles of the Declaration of Helsinki and approved by the Tosei General Hospital Institutional Review Board (IRB No. 554). The trial was registered in the university hospital medical 
information network Clinical Trial Registry (UMIN-CTR) (UMIN000021901). All participants provided written informed consent before participation.

\section{Consent for publication}

Not applicable.

\section{Competing interests}

TK, KK, YK report lecture fees from Teijin Pharma Limited, Fukuda Denshi Co., Ltd., and Philips Respironics GK. outside the submitted work. TY reports lecture fees from Teijin Pharma Limited, Philips Respironics GK., and Koike Medical CO., Ltd. outside the submitted work. ES is an employee of Pacific Medico Co., Ltd. Other authors have no conflicts of interest to report.

\section{Author details}

${ }^{1}$ Department of Respiratory Medicine and Allergy, Tosei General Hospital, 160 Nishioiwake-cho, Seto, Aichi 489-8642, Japan. ${ }^{2}$ Department of Respiratory Medicine, Nagoya University Graduate School of Medicine, Nagoya, Aichi, Japan. ${ }^{3}$ Center for Advanced Medicine and Clinical Research, Nagoya University Hospital, Nagoya, Aichi, Japan. ${ }^{4}$ Pacific Medico Co., Ltd. Chiyoda-ku, Tokyo, Japan.

Received: 27 March 2019 Accepted: 19 February 2020

Published online: 24 February 2020

\section{References}

1. Raghu G, Remy-Jardin M, Myers JL, Richeldi L, Ryerson CJ, Lederer DJ. et al; American Thoracic Society, European Respiratory Society, Japanese respiratory Society, and Latin American Thoracic Society. Diagnosis of idiopathic pulmonary fibrosis. An official ATS/ERS/JRS/ALAT clinical practice guideline. Am J Respir Crit Care Med. 2018;198:e44-68.

2. Travis WD, Costabel U, Hansell DM, King TE Jr, Lynch DA, Nicholson AG, et al. ATS/ERS Committee on Idiopathic Interstitial Pneumonias An official American Thoracic Society/European Respiratory Society statement: Update of the international multidisciplinary classification of the idiopathic interstitial pneumonias. Am J Respir Crit Care Med. 2013;188:733-48

3. Nishiyama O, Taniguchi H, Kondoh Y, Kimura T, Kato K, Kataoka K, et al. A simple assessment of dyspnoea as a prognostic indicator in idiopathic pulmonary fibrosis. Eur Respir J. 2010;36:1067-72.

4. Flaherty KR, Andrei AC, Murray S, Fraley C, Colby TV, Travis WD, et al. Idiopathic pulmonary fibrosis: prognostic value of changes in physiology and six-minute-walk test. Am J Respir Crit Care Med. 2006;174:803-9.

5. Fell CD, Liu LX, Motika C, Kazerooni EA, Gross BH, Travis WD, et al. The prognostic value of cardiopulmonary exercise testing in idiopathic pulmonary fibrosis. Am J Respir Crit Care Med. 2009;179:402-7.

6. Nishiyama O, Miyajima H, Fukai Y, Yamazaki R, Satoh R, Yamagata T, et al. Effect of ambulatory oxygen on exertional dyspnea in IPF patients without resting hypoxemia. Respir Med. 2013;107:1241-6.

7. Visca D, Mori L, Tsipouri V, Fleming S, Firouzi A, Bonini M, et al. Effect of ambulatory oxygen on quality of life for patient with fibrotic lung disease (AmbOx): a prospective, open-label, mixed-method, crossover randomized controlled trial. Lancet Respir Med. 2018;6:759-70.

8. Edvardsen A, Jarosch I, Grongstad A, Wiegand L, Gloeckl R, Kenn K, et al. A randomized cross-over trial on the direct effects of oxygen supplementation therapy using different devices on cycle endurance in hypoxemic patients with interstitial lung disease. PLoS One. 2018;13: e0209069.

9. Bell EC, Cox NS, Goh N, Glaspole I, Westall GP, Watson A, et al. Oxygen therapy for interstitial lung disease: a systematic review. Eur Respir Rev. 2017;26. https://doi.org/10.1183/16000617.0080-2016.

10. Frat JP, Thille AW, Mercat A, Girault C, Ragot S, Perbet S, et al. FLORALI study group; REVA network. High-flow oxygen through nasal cannula in acute hypoxemic respiratory failure. N Engl J Med. 2015;372:2185-96.

11. Stéphan F, Barrucand B, Petit P, Rézaiguia-Delclaux S, Médard A, Delannoy B, BiPOP Study Group, et al. High-flow nasal oxygen vs noninvasive positive airway pressure in hypoxemic patients after cardiothoracic surgery: a randomized clinical trial. JAMA. 2015;313:2331-9.

12. Maggiore SM, Idone FA, Vaschetto $R$, et al. Nasal high-flow versus venturi mask oxygen therapy after extubation. Effects on oxygenateon, comfort, and clinical outcome. Am J Respir Crit Care Med. 2014;190:282-8.

13. Fraser JF, Spooner AJ, Dunster KR, Anstey CM, Corley A. Nasal high flow oxygen therapy in patients with COPD reduces respiratory rate and tissue carbon dioxide while increasing tidal and end-expiratory lung volumes; a randomized crossover trial. Thorax. 2016;71:759-61.

14. Puente-Maestu L, Palange P, Casaburi R, Laveneziana P, Maltais F, Neder JA, et al. Use of exercise testing in the evaluation of interventional efficacy: an official ERS statement. Eur Respir J. 2016;47:479-60.

15. Arizono S, Taniguchi H, Sakamoto K, Kondoh Y, Kimura T, Kataoka K, et al. Endurance time is the most responsive exercise measurement in idiopathic pulmonary fibrosis. Respir Care. 2014;59:1108-15.

16. Chatila W, Nugent T, Vance G, Gaughan J, Criner GJ. The effects of high-flow vs low-flow oxygen on exercise in advanced obstructive airways disease. Chest. 2004;126:1108-15

17. Bianchi L, Foglio K, Pagani M, Vitacca M, Rossi A, Ambrosino N. Effects of proportional assist ventilation on exercise tolerance in COPD patients with chronic hypercapnia. Eur Respir J. 1998;11:422-7.

18. American Thoracic Society, American College of Chest Physicians. ATS/ACCP Statement on cardiopulmonary exercise testing. Am J Respir Crit Care Med. 2003;167:211-77.

19. Galiè N, Humbert M, Vachiery JL, Gibbs S, Lang I, Torbicki A, et al. 2015 ESC/ ERS guidelines for the diagnosis and treatment of pulmonary hypertension: the joint task force for the diagnosis and treatment of pulmonary hypertension of the European Society of Cardiology (ESC) and the European Respiratory Society (ERS): endorsed by: Association for European Paediatric and Congenital Cardiology (AEPC), International Society for Heart and Lung Transplantation (ISHLT). Eur Respir J. 2015;46:903-75.

20. Nathan SD, Shlobin OA, Barnett SD, Saggar R, Belperio JA, Ross DJ, et al. Right ventricular systolic pressure by echocardiography as a predictor of pulmonary hypertension in idiopathic pulmonary fibrosis. Respir Med. 2008; 102:1305-10.

21. Bräunlich J, Beyer D, Mai D, Hammerschmidt S, Seyfarth HJ, Wirtz H. Effects of nasal high flow on ventilation in volunteers, COPD and idiopathic pulmonary fibrosis patients. Respiration. 2013;85:319-25.

22. McKinstry S, Pilcher J, Bardsley G, Berry J, Van de Hei S, Braithwaite I, et al. Nasal high flow therapy and PtCO2 in stable COPD: a randomized controlled cross-over trial. Respirology. 2017;23:378-84.

23. Chanques G, Constantin JM, Sauter M, Jung B, Sebbane M, Verzilli D, et al. Discomfort associated with underhumidified high-flow oxygen therapy in critically ill patients. Intensive Care Med. 2009;35:996-1003.

24. Parke RL, Ecceleston ML, McGuinness SP. The effects of flow on airway pressure during nasal high-flow oxygen therapy. Respir Care. 2011;56:1151-5.

25. Onodera $Y$, Akimoto $R$, Suzuki H, Okada M, Nakane M, Kawamae K. A highflow nasal cannula system with relatively low flow effectively washes out $\mathrm{CO}_{2}$ from the anatomical dead space in a sophisticated respiratory model made by a 3D printer. Intensive Care Med Exp. 2018;6:7. https://doi.org/10. 1186/s40635-018-0172-7.

26. O'Donnell DE, Sanij R, Younes M. Improvement in exercise endurance in patients with chronic airflow limitation using continuous positive airway pressure. Am Rev Respir Dis. 1988;138:1510-4.

27. Keilty SEJ, Ponte J, Fleming TA, Moxham J. Effect of inspiratory pressure support on exercise tolerance and breathlessness in patients with severe stable chronic obstructive pulmonary disease. Thorax. 1994;49:990-4.

28. Moderno EV, Yamaguti WP, Schettino GP, Kairalla RA, Martins MA, Carvalho CR, et al. Effects of proportional assisted ventilation on exercise performance in idiopathic pulmonary fibrosis patients. Respir Med. 2010;104:134-41.

29. Nagata K, Kikuchi T, Horie T, Shiraki A, Kitajima T, Kadowaki T, et al. Domiciliary high-flow nasal cannula oxygen therapy for patients with stable hypercapnic chronic obstructive pulmonary disease. A multicenter randomized crossover trial. Ann Am Thorac Soc. 2018;15:432-9.

30. Storgaard LH, Hockey HU, Laursen BS, Weinreich UM. Long-term effects of oxygen-enriched high-flow nasal cannula treatment in COPD patients with chronic hypoxemic respiratory failure. Int J Chorn Obstruct Pulmon Dis. 2018;13:1195-205

31. Perez-Bogerd S, Wuyts W, Barbier V, Demeyer H, Van Muylem A, Janssens W et al. Short and long-term effects of pulmonary rehabilitation in interstitial lung diseases: a randomized controlled trial. Respir Res. 2018;19:182.

32. Tonelli R, Cocconcelli E, Lanini B, Romagnoli I, Florini F, Castaniere I, et al. Effectiveness of pulmonary rehabilitation in patients with interstitial lung disease of different etiology: a multicenter prospective study. BMC Pulm Med. 2017;17:130

33. Dowman LM, McDonald CF, Hill CJ, Lee AL, Barker K, Boote C, et al. The evidence of benefits of exercise training in interstitial lung disease: a randomised controlled trial. Thorax. 2017;72:610-9. 
34. Juge PA, Lee JS, Ebstein E, Furukawa H, Dobrinskikh E, Gazal S, et al. MUC5B promoter varian and rheumatoid arthritis with interstitial lung disease. N Encl J Med. 2018;379:2209-19.

35. Ley B, Newton CA, Arnould I, Elicker BM, Henry TS, Vittinghoff E, et al. The MUC5B promoter polymorphism and telomere length in patients with chronic hypersensitivity pneumonitis: an observational cohort-control study. Lancet Respir Med. 2017;5:639-47.

36. Newton CA, Batra K, Torrealba J, Kozlitina J, Glazer CS, Aravena C, et al. Telomere-related lung fibrosis is diagnostically heterogeneous but uniformly progressive. Eur Respir J. 2016;48:1710-20.

37. Watanabe F, Taniguchi H, Sakamoto K, Kondoh Y, Kimura T, Kataoka K, et al. Quadriceps weakness contributes to exercise capacity in nonspecific interstitial pneumonia. Respir Med. 2013;107:622-8.

38. Dias OM, Baldi BG, Ferreira JG, Cardenas LZ, Pennati F, Salito C, et al. Mechanisms of exercise limitation in patients with chronic hypersensitivity pneumonitis. ERJ Open Res. 2018;4. https://doi.org/10.1183/23120541.00043-2018.

\section{Publisher's Note}

Springer Nature remains neutral with regard to jurisdictional claims in published maps and institutional affiliations.

Ready to submit your research? Choose BMC and benefit from:

- fast, convenient online submission

- thorough peer review by experienced researchers in your field

- rapid publication on acceptance

- support for research data, including large and complex data types

- gold Open Access which fosters wider collaboration and increased citations

- maximum visibility for your research: over $100 \mathrm{M}$ website views per year

At BMC, research is always in progress.

Learn more biomedcentral.com/submissions 